\title{
Serum IL-6 Is Increased During Performance Cycling After Energy Drink Consumption
}

Jonathan P. Woodson, Melody D. Phillips, Jacob W. Ross, Kelyn S. Rola, Kenneth V. Christensen. Texas Christian University, Ft. Worth, TX Master's Degree Candidate

Energy Drinks (ED) have become popular preexercise supplements due to the stimulant effects of their ingredients such as caffeine. Other ingredients including carbohydrate $(\mathrm{CHO})$, glucuronolactone and taurine may also contribute to performance enhancement. Purpose: The purpose of this study was to investigate the influence of energy drink consumption on cycling performance, substrate oxidation and immune-related variables. Methods: This study was a blinded, randomized, cross-over design with 3 experimental conditions. Eleven trained male cyclists (mean age $33.4 \pm 8.9 \mathrm{yr}$, body mass $81 \pm 7.6 \mathrm{~kg}, \mathrm{VO}_{2 \max }$ $51.72 \pm 3.4 \mathrm{ml}^{*} \mathrm{~kg}^{-1 *} \mathrm{~min}^{-1}$ ) consumed 3 different $500 \mathrm{ml}$ beverages: 1) Energy Drink (ED1- $2.0 \mathrm{~g}$ taurine, $1.2 \mathrm{~g}$ glucoronolactone, $160 \mathrm{mg}$ caffeine, $54 \mathrm{~g} \mathrm{CHO}, 40$ $\mathrm{mg}$ niacin, $10 \mathrm{mg}$ pantothenic acid, $10 \mathrm{mg}$ vitamin $\mathrm{B} 6$, and $10 \mu \mathrm{g}$ vitamin B12), 2) cola matched for caffeine and $\mathrm{CHO}$ (ED2), or 3) non-caloric sparkling water (ED3) 55 min prior to racing. Performance was measured as time to complete a 25-mile simulated road race. Blood was collected pre-drink (PrD), 30 minutes after drink (pre-exercise, PrEx), during exercise at mile 5 (M5), mile 15 (M15), and immediately (PoEx) \& 30 min post-exercise (30min). Results: Performance time was not different among trials (ED1 4117 \pm 161 , ED2 4132 \pm 230 , ED3 $4173 \pm 225 \mathrm{~s})$. PrEx IL-6 was not different among ED1, 2 or $3(0.61 \pm 0.09$, $0.78 \pm 0.1,0.56 \pm 0.07 \mathrm{pg}^{*} \mathrm{~mL}^{-1}$, respectively). PoEx IL-6 was greatest after ED1 while ED2 IL-6 response was greater than ED3 $(10.2 \pm 1.6,6.7 \pm 0.6,4.8 \pm 0.7$ $\left.\mathrm{pg}^{*} \mathrm{ml}^{-1}, \mathrm{p}<0.001\right)$. IL-6 declined after ED1 \& ED2 by 30min, but remained significantly greater than baseline after all trials $(5.3 \pm 1,4.1 \pm 0.5,3.6 \pm 0.7$, at $30 \mathrm{~min}, \mathrm{ED} 1,2$ and 3, respectively, $p<0.001$ ). Cycling increased leukocyte number in all conditions with ED1 leukocyte number greater than that of ED3 at M15 (9.8 $\left.\pm 0.6,8.5 \pm 0.3 \times 10^{\wedge} 6 \mathrm{cell} / \mathrm{mL}, \mathrm{p}=0.012\right)$. Mean fat oxidation was greater in ED3 compared to ED2 $\left(0.43 \pm 0.06,0.28 \pm 0.04 \mathrm{~g}^{*} \mathrm{~min}^{-1}, \mathrm{p}=0.033\right)$ but did not differ between ED1 $(0.32 \pm 0.06)$ and ED3. Fat oxidation was increased in all trials from M5 $(0.27 \pm 0.06,0.28 \pm 0.05,0.40 \pm 0.07, E D 1,2,3$ respectively) to M15 $(0.46 \pm 0.08,0.42 \pm 0.06,0.61 \pm 0.06$, ED1, 2, 3 respectively, $p<0.001)$.

Conclusion: Coingestion of caffeine and $\mathrm{CHO}$ prior to endurance cycling significantly increased the IL-6 response to exercise, and the additional ingredients of ED1 appear to have further augmented this response. ED1 also appears to have increased leukocyte number compared to ED3 and fat oxidation so that it was similar to that observed during ED3. The observed results may be consequent to SNS stimulation via caffeine or other ingredients in ED1. 